\title{
Efficiency of Lumbar Epidural and Spinal Anesthesia in Elective Caesarean Section in Bangladeshi Women
}

Dr. Md. Nurul Amin ${ }^{1 *}$, Dr. Farhana Jaya Chowdury ${ }^{2}$, Dr. Md. Golam Mowla ${ }^{3}$, Dr. Md. Abdur Rahman

${ }^{1}$ Associate Professor and Head, Dept. of Anaesthesiology, Sylhet Women's Medical College, Sylhet, Bangladesh

${ }^{2}$ Assistant Professor, Dept. of Paediatrices, Sylhet Women's Medical College, Sylhet, Bangladesh

${ }^{3}$ Associate Professor, Dept. of Surgery, Sylhet Women's Medical College, Sylhet, Bangladesh

${ }^{4}$ Senior Consultant, Dept. of Anaesthesiology, Sadar Hospital Jhenaidah, Bangladesh

DOI: $10.36347 /$ sjams.2021.v09i01.023

| Received: 28.12.2020 | Accepted: 13.01.2021 | Published: 20.01.2021

*Corresponding author: Dr. Md. Nurul Amin

Abstract

Original Research Article

Background: The Caesareans (C/S) segment is preferably carried out with regional procedures such as spinal and anesthesia. Both are preferred to general anesthesia, which helps the mother to stay wakeful when administering caesarean. Objective: To assess effectiveness of lumbar epidural and spinal sedation in elective cesarean segment of women in Bangladesh. Methods: This experimental study is led at tertiary medical college hospital, from March 2018 to March 2019 where composed educated assent from 150 patients were gotten for this test study. The patients selected for the study was divided into two groups: Group - I (Spinal): 50 Patients selected, Group - II (Epidural): 50 patients selected. Result: During the study, $90 \%$ patients were from rural and according intraoperative complication in groupA, $35 \%$ had hypotension where as in group-B it was $11 \% .37 \%$ patients were Highly satisfied in group-A where as in group-B it was $61 \%$ In group-A $71 \%$ patients were complaining of pain in the first night where as in group-B it was 6\%. Conclusion: The hypotension procedure is required more often than the epidural approach for women anesthesized using a spinal anesthesia technique. Since hypotension may have a detrimental impact on the infant, further study is needed to examine the neonatal outcomes of spinal anesthesia.

Keywords: Lumbar epidural anaesthesia, spinal anaesthesia, cesarean section (CS).

Copyright $\left({ }_{0} 2021\right.$ The Author(s): This is an open-access article distributed under the terms of the Creative Commons Attribution 4.0 International License (CC BY-NC 4.0) which permits unrestricted use, distribution, and reproduction in any medium for non-commercial use provided the original author and source are credited.

\section{INTRODUCTION}

A Caesarean Section (CS) is usually undertaken if the infant or mother's lives are put at risk by a vaginal delivery. But it has also been carried out lately at the mother's invitation. For an optional CS, the mother may be examined and the form of anesthesia calculated. Regional anesthesia is worthwhile contrasted and general anesthesia so the mother stays wakeful during birth [1, 2].

Although spinal and epidural procedures are the most common regional anesthesia for CS, the acceptability in various regions of the world varies in differently [3]. According to ASA guidelines, there are no definitive answers to the decision of the spinal or epidural cell. In a new hospital study performed at
South-West Thames in the UK, the prevalence of regional anesthesia was $94.9 \%$, with $86.6 \%$ of these patients being dissected by spinal anesthesia [4].

\section{OBJECTIVE}

\section{General objective}

- To assess effectiveness of lumbar epidural and spinal sedation in elective cesarean segment of women in Bangladesh.

\section{Specific objective}

- To detect intra-operative events between two groups

- To identify the post-operative outcomes between two groups. 


\section{Methodology}

\begin{tabular}{|l|l|}
\hline Type of study & Experimental study \\
\hline Place of study & Tertiary medical college and hospital \\
\hline Study period & March 2018 to March 2019 \\
\hline Study population & Written informed consent from 100 patients were obtained for this experimental study. \\
\hline Sampling technique & Purposive \\
\hline
\end{tabular}

\section{METHOD}

- During the study, after taking consent from the patients. The patients had the ordinary history of single pregnancy and an ASA actual status I and II. Pre-anaesthetic assessments were done on the day before surgery. The patients with suspected or show draining aggravations, net anomaly in vertebral section, contamination in the back, presence of liver and kidney sicknesses, understanding taking anticoagulant and patient with pregnancy prompted hypertension (PIH) or preeclamptia were barred from the examination. The patients selected for the study was divided into two groups: Group - I (Spinal): 50 Patients selected, Group - II (Epidural): 50 patients selected.

\section{Data AnAlysis}

- After collection, data were entered into a personal computer and were edited, analyzed, plotted in graphs and tables. Data were analyzed by chi square test, Mann Whitney U tests, using the statistical package for social sciences (SPSS) version 20 .

\section{RESULTS}

In table-1 shows age distribution of the patients where most of the patients in both groups belong to $31-40$ years age group, $57 \%$ and $64 \%$. The following table is given below in detail:

Table-1: Age distribution of the patients

\begin{tabular}{|l|l|l|}
\hline Age group & Group-A, \% & Group-B, \% \\
\hline $21-30$ & $36 \%$ & $31 \%$ \\
\hline $31-40$ & $57 \%$ & $64 \%$ \\
\hline $41-50$ & $8 \%$ & $5 \%$ \\
\hline
\end{tabular}

In table-2 shows educational status of the patients where in group-A, only $5 \%$ patients were completed their graduation where in group-B $9 \%$. The following table is given below in detail:

Table-2: Distribution of the patients according to educational status of the patients

\begin{tabular}{|l|l|l|}
\hline Education of patients' parents & Group-A, \% & Group-B, \% \\
\hline Illiterate & $20 \%$ & $21 \%$ \\
\hline Primary & $6 \%$ & $12 \%$ \\
\hline Secondary & $21 \%$ & $14 \%$ \\
\hline Higher-secondary & $43 \%$ & $11 \%$ \\
\hline Graduation or more & $5 \%$ & $9 \%$ \\
\hline
\end{tabular}

In table-3 shows parity distribution of the study group, where in group-A $52 \%$ women were in their first pregnancy followed by $28.30 \%$ were 2 nd pregnancy, $19.70 \%$ were multi gravid women. Where as in gathering B 53\% women were in their first pregnancy followed by $28 \%$ were second pregnancy, $19 \%$ were multi gravid women. The following table is given below in detail:

Table-3: Parity distribution of the pregnant women

\begin{tabular}{|l|l|l|}
\hline Parity & Group-A, \% & Group-B, \% \\
\hline Prime gravida & $52 \%$ & $53 \%$ \\
\hline 2nd pregnancy & $28.30 \%$ & $28 \%$ \\
\hline Multi gravida & $19.70 \%$ & $19 \%$ \\
\hline
\end{tabular}

In figure-1 shows residential area of the patients where $90 \%$ patients were from rural. The following figure is given below in detail:

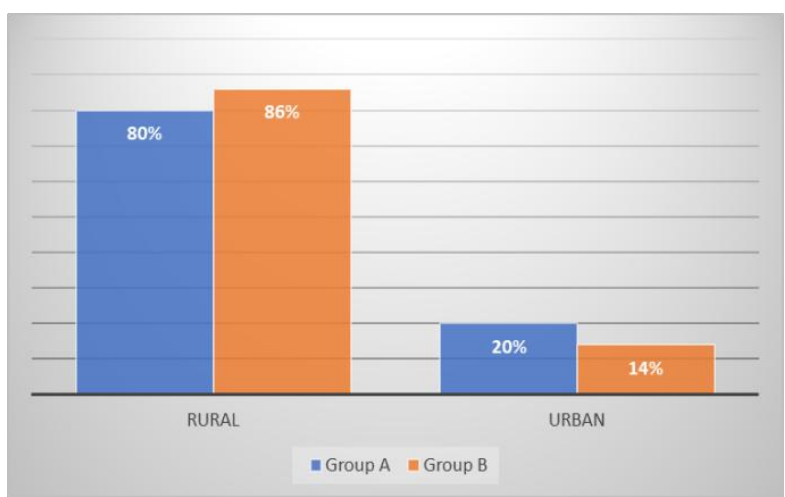

Fig-1: Residential area of the patients

In table- 4 shows the baseline values of mean BP and Heart rate where there is no significant change between the two groups. The following table is given below in detail: 
Table-4: The baseline values of mean BP and Heart rate.

\begin{tabular}{|l|l|l|}
\hline Variable & Group-A & Group-B \\
\hline SBP in $\mathrm{mm}$ of $\mathrm{Hg}$ & $117.58 \pm 12.10$ & $119.31 \pm 11.97$ \\
\hline DBP in $\mathrm{mm}$ of $\mathrm{Hg}$ & $77.58 \pm 9.62$ & $78.26 \pm 9.22$ \\
\hline MAP in $\mathrm{mm}$ of $\mathrm{Hg}$ & $92.6 \pm 6.49$ & $93.8 \pm 5.32$ \\
\hline HR in beats per min. & $80.2 \pm 7.30$ & $82.48 \pm 6.27$ \\
\hline
\end{tabular}

In figure-2 shows comparison of intra operative events between two groups where in group-A, $35 \%$ hypotension had where as in group-B it was $11 \%$. The figure is given below in detail:

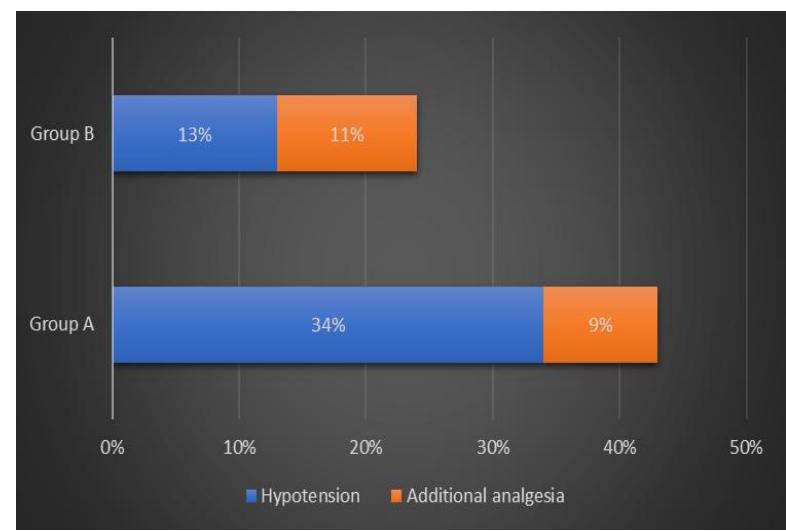

Fig-2: Comparison of intra operative events between two groups

In table-4 shows Level of maternal satisfaction where in group-A, $37 \%$ patients were highly satisfied where as in group-B it was $61 \%$. The following table is given below in detail:

Table-4: Level of maternal satisfaction

\begin{tabular}{|l|l|l|}
\hline Variable & Group-A & Group-B \\
\hline Highly satisfied & $37 \%$ & $61 \%$ \\
\hline Fairly satisfied & $42 \%$ & $24 \%$ \\
\hline Not satisfied & $21 \%$ & $15 \%$ \\
\hline
\end{tabular}

In figure-3 shows post-operative interview of the mothers where in group-A $71 \%$ patients were complaining of pain in the first night where as in group$\mathrm{B}$ it was $6 \%$. The following figure is given below in detail:

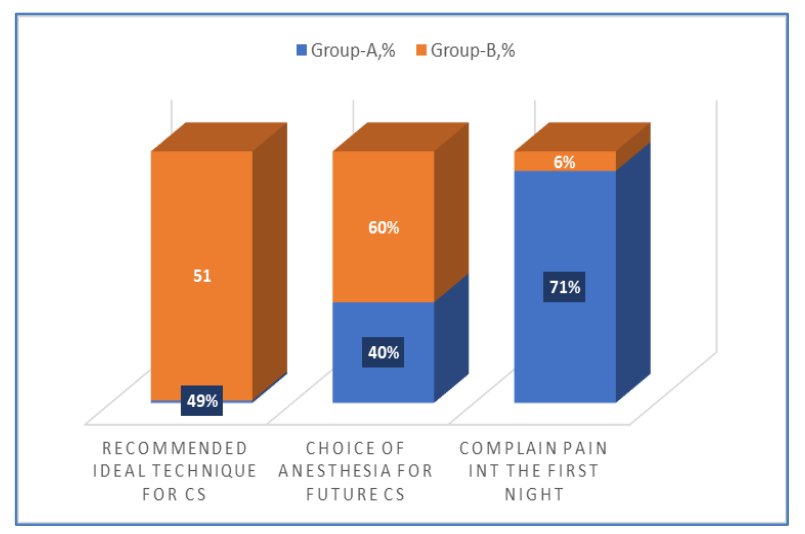

Fig-3: Post-operative interview of the mothers

\section{DisCUSSION}

Lower susceptibility to medications is triggered by regional anesthesia [5, 6]. But spinal technology places mother and fetus at highest risk of hypotension [7]. Although epidural procedures are not frequent for the occurrence of hypotension, they occur quicker and faster in the backbone method. Maternal arterial mean (MAP) and uteroplacental perfusion are decreased by hypotension [8].

It was discovered that mothers of epidural gathering were exceptionally fulfilled in contrast with spinal gathering and the quantity of mothers not happy with the sedative method is high in spinal gathering $(\mathrm{P}<$ 0.01). Which very like other examination [9].

Post-operative pain relief was better kept up by nonstop implantation of analgesics through epidural catheter. Though, absense of pain in the spinal gathering was kept up with intramuscular narcotics or NSAIDs.

In one study reported that, in Spinal group, 20 (68.97\%) patients complained of pain in the first night of the post-operative period; while in epidural group the figure was only one $(3.45 \%),(\mathrm{P}=0.000)[7]$.

Fifteen patients from spinal gathering and 25 patients from epidural gathering have picked the current sedative procedure for their future CS and furthermore suggested as an ideal strategy for CS [10]. Which was quite similar to our study where we found that in the postoperative interview, a significantly higher number of mothers of epidural group $(\mathrm{P}<0.01)$ told that they did not feel pain on the postoperative night. The mothers who were agreeable in the intraoperative period and the individuals who didn't feel torment in the post-usable period had picked the procedure for their future cesarean conveyance and furthermore suggested the strategy as an ideal for elective cesarean segment $(\mathrm{P}<$ $0.01)$.

\section{Conclusion}

The hypotension procedure is required more often than the epidural approach for women anesthesized using a spinal anesthesia technique. Since hypotension may have a detrimental impact on the infant, further study is needed to examine the neonatal outcomes of spinal anesthesia.

\section{REFERENCE}

1. Reisner L. Anesthesia for cesarean delivery.Clinical Obstetrics and Gynecology. 1987: 30(3):539-51.

2. Jenkins J, Khan MM. Anaesthesia for Caesarean section: a survey in a UK regionfrom. 1992 to 2002. Anaesthesia. 2003; 58(11):1114-8.

3. Hawkins JL, Koonin LM, Palmer SK, Gibbs CP. 
Anesthesia-related deaths during obstetric delivery in the United States 1979-1990, Anesthesiology. 1997; 86(2): 277-84.

4. Hibbard BM, Anderson MM, Drife JO, Tighe JR, Gordon G, Willatts S. Deaths associated with anaesthesia. In: Rubery E, Bourdillon P editor(s). Report on confidential enquiries into maternal deaths in the United Kingdom. 1991-1993. Norwich: HMSO. 1996:87-102.

5. Ezri T, Szmuck P, Evron S, Geva D, Hagay Z, Katz J. Difficult airway in obstetric anesthesia: a review. Obstetrical and Gynecological Survey. 2001; 56(10): 631-41.

6. Weeks SK. Postpartum headache. In: Chestnut DH eds. Obstetric anaesthesia. St. Louis: Mosby; 1999:
621-38.

7. Weir EC. The sharp end of the dural puncture. BMJ. 2000; 320:127.

8. Hawkins JL, Beaty BR, Gibbs CP. Update on obstetric anesthesia practices in the US. Anesthesiology.1999; 90(4AS):53A.

9. Scott DB. Tunstall ME. Serious complications associated with epidural/spinal blockade in obstetrics: a two-year prospective study. n Journal of Obstetric Anesthesia.1995; 4: 133-9.

10. Villar J, Valladares E, Wojdyla D, Zavaleta N, Carroli G, Velazco A, Shah A. Caesarean delivery rates and pregnancy outcomes: the 2005 WHO global survey on maternal and perinatal health in Latin America. Lancet. 2006; 367:1819-1829. 